This document is the Accepted Manuscript version of a Published Work that appeared in final form in Chemistry of Materials, copyright (c) American Chemical Society after peer review and technical editing by the publisher.

To access the final edited and published work see: https://doi.org/10.1021/acs.chemmater.6b01968 


\title{
Ultrafast Epitaxial Growth Kinetics in Functional Oxide Thin Films Grown by Pulsed Laser Annealing of Chemical Solutions
}

\author{
Albert Queraltó, ${ }^{* \dagger}$ Angel Pérez del Pino, ${ }^{\dagger}$ María de la Mata, ${ }^{\dagger, \S}$ Jordi Arbiol, ${ }^{\S, \ddagger}$ Mar Tristany ${ }^{\dagger}, \mathrm{Xa}^{-}$ \\ vier Obradors ${ }^{\dagger}$, Teresa Puig ${ }^{\dagger}$ \\ † Institut de Ciència de Materials de Barcelona, Consejo Superior de Investigaciones Científicas (ICMAB-CSIC) \\ Campus UAB, o8193 Bellaterra, Catalonia, Spain. \\ $\S$ Catalan Institute of Nanoscience and Nanotechnology (ICN2), CSIC and The Barcelona Institute of Science and Technology \\ Campus UAB, 08193 Bellaterra, Catalonia, Spain. \\ ‡ Institució Catalana de Recerca i Estudis Avançats (ICREA) \\ o8010 Barcelona, Catalonia, Spain.
}

\begin{abstract}
The crystallization process and physical properties of different functional oxide thin films $\left(\mathrm{Ce}_{0.9} \mathrm{Zr}_{\mathrm{o} .1} \mathrm{O}_{2-\mathrm{y}}, \mathrm{LaNiO}_{3}\right.$, $\mathrm{Ba}_{0.8} \mathrm{Sr}_{0.2} \mathrm{TiO}_{3}$ and $\left.\mathrm{La}_{0.7} \mathrm{Sr}_{0.3} \mathrm{MnO}_{3}\right)$ on single crystal substrates $\left(\mathrm{Y}_{2} \mathrm{O}_{3}: \mathrm{ZrO}_{2}, \mathrm{LaAlO}_{3}\right.$ and $\left.\mathrm{SrTiO}_{3}\right)$ are studied by pulsed laser annealing (PLA). A Nd:YAG laser source ( $\lambda=266 \mathrm{~nm}, 10 \mathrm{~Hz}$ and $\tau \sim 3 \mathrm{~ns}$ ) is employed to crystallize chemical solution deposited (CSD) amorphous/nanocrystalline films in atmospheric conditions. We provide new insight on the influence of photochemical and photothermal interactions on the epitaxial crystallization kinetics of oxide thin films during the transformation from amorphous/polycrystalline material (i.e. atomic diffusion, epitaxial growth rates and activation energies of nucleation and crystallization). The epitaxial growth is investigated by varying the laser fluence and the applied number of pulses. The morphology, structure and epitaxial evolution of films are evaluated by means of atomic force and transmission electron microscopies, and X-ray diffraction. Highly epitaxial oriented films of $20-40 \mathrm{~nm}$ in thickness are obtained by PLA. The crystallization kinetics of laser treatments is determined to be orders of magnitude faster than thermal treatments with similar activation energies (1.5-4.1 eV), mainly due to the large temperature gradients inducing modified atomic diffusion mechanisms derived mainly from photothermal interactions, as well as a minor contribution of photochemical effects. The fast heating rates achieved by PLA also contribute to the fast epitaxial growth due to reduced coarsening of polycrystalline material. The measurement of the physical properties (electrical resistivity and magnetism) of laser processed CSD films has revealed significantly good functionalities, close to those of thermally grown films, but with much shorter processing times.
\end{abstract}

\section{INTRODUCTION}

Crystallization of functional oxide is a central topic in materials science that has drawn much attention in the past decades. Especially, thanks to the development of nanoscience and nanotechnology which have allowed the production of dimensionally constrained materials with great potential for multiple applications and outstanding physical properties in fields such as ferromagnetism, ferroelectricity, colossal magnetoresistance, multiferroicity, superconductivity or photocatalysis. ${ }^{1-6}$

Solution-based methods like the chemical solution deposition (CSD) have demonstrated high versatility, cost-effectiveness and scalability in the fabrication of highly crystalline functional oxide heterostructures with complex compositions as compared to more established physical methods (sputtering or pulsed laser deposition). ${ }^{7^{-}}$ ${ }^{9}$ Oxide crystallization by CSD involves the use of high temperature thermal treatments which are time consuming and limit their growth on temperature sensitive sub- strates. Over the last decades, laser irradiation, also known as laser annealing, has arisen as an alternative processing methodology to avoid the constraints of pure thermal techniques for materials processing due to the fast, versatile and localized nature of lasers. ${ }^{10}$ Laser systems working in continuous wave (CW) or pulsed modes at wavelengths in the infrared (IR), visible (Vis) and ultraviolet (UV) ranges, have been employed to induce complex phenomena. For instance, laser-induced local diffusion of species has been reported to be key in the growth of TiN microcolumns and $\mathrm{Cu}$ films from $\mathrm{CuO}$ nanoparticles with CW and pulsed IR lasers (Nd:YAG and Yb-doped fiber lasers), ${ }^{11}{ }^{12}$ but also in InGaAs/GaAs quantum dots and $\mathrm{RbLaNb}_{2} \mathrm{O}_{7}$ films using pulsed UV excimer lasers. ${ }^{13,}{ }^{14}$ $\mathrm{CW}$ and pulsed diode and Nd:YAG lasers with wavelengths in the IR and UV range have also been used for the decomposition of metalorganic solutions, the densification of sol-gel films, and the fabrication of crystalline 
patterned oxide nanostructures such as $\mathrm{Ce}_{\text {o.9 }} \mathrm{Zr}_{\text {o.1 }} \mathrm{O}_{2-y}$ (CZO), $\alpha-\mathrm{Fe}_{2} \mathrm{O}_{3}$ and $\mathrm{ZrO}_{2}$ with high spatial resolution. ${ }^{15-18}$

Laser crystallization of CSD precursor films has been mostly investigated for a broad range of polycrystalline oxides such as $\mathrm{ZrO}_{2}, \mathrm{TiO}_{2}$, undoped and $\mathrm{Sn}$-doped $\mathrm{In}_{2} \mathrm{O}_{3}$, $\mathrm{Ba}_{1-\mathrm{x}} \mathrm{Sr}_{\mathrm{x}} \mathrm{TiO}_{3}(\mathrm{x}=0.2$ and 0.3$)$ and $(\mathrm{Pb}, \mathrm{La})(\mathrm{Zr}, \mathrm{Ti}) \mathrm{O}_{3}$ using diode, excimer and Nd:YAG lasers in the IR, Vis and UV ranges. ${ }^{17-24}$ In addition, some works have grown polycrystalline Al-doped $\mathrm{ZnO}$ from sputtered amorphous films with IR diode and UV excimer lasers in CW and pulsed modes. ${ }^{25,}{ }^{26}$ Nevertheless, UV lasers are the best choice for oxide crystallization due to their large absorption at those wavelengths. Tsuchiya et al. have reported successful epitaxial growth with oxides like $\mathrm{VO}_{2}$, perovskite manganites (LMO, LSMO), $\mathrm{Pb}(\mathrm{Zr}, \mathrm{Ti}) \mathrm{O}_{3}$ and $\mathrm{YBa}_{2} \mathrm{Cu}_{3} \mathrm{O}_{7}$ using UV excimer lasers. ${ }^{27-32}$ In addition, we have also reported growth of epitaxial oxides like $\mathrm{Ce}_{0.9} \mathrm{Zr}_{\text {o.1 }} \mathrm{O}_{2-y}$ and $\mathrm{Ba}_{0.8} \mathrm{Sr}_{\mathrm{o.2}} \mathrm{TiO}_{3} .{ }^{33}, 34$ These works have proposed different approaches to investigate the fundamental thermodynamic and kinetic principles of laser crystallization of CSD films. However, there are still some open questions that we wanted to investigate further. Essentially, a general overview that evaluates the extent to what photochemical and photothermal interactions influence the laser crystallization kinetics (i.e. atomic diffusion and activation energies) which depends on the type of laser employed; but also how this kinetics compares to that of thermal annealing. In this work, we aim to provide additional insights on the underlying laser epitaxial crystallization mechanisms by comparing different oxide thin films and their functional properties, but also with equivalent films crystallized with thermal treatments. We want to understand the fast transformation from the decomposed metalorganic chemical precursors to the epitaxial film crystallization. We have chosen the following high performant functional oxide materials for our study: zirconium-doped ceria $\left(\mathrm{Ce}_{0.9} \mathrm{Zr}_{\mathrm{o} .1} \mathrm{O}_{2-\mathrm{y}}\right.$ or $\left.\mathrm{CZO}\right)$, which can be used as dielectric component in electronic devices or as a buffer layer for high temperature superconducting coated conductors since it has high mechanical and chemical stability, and high dielectric constant..$^{35-37}$ Lanthanum nickelate $\left(\mathrm{LaNiO}_{3}\right.$ or LNO) is a highly metallic oxide at room temperature that can be employed as an electrode to integrate other oxide materials in electronic devices, ${ }^{38}$ and it also presents interesting photoelectrocatalytic properties for water splitting applications. ${ }^{39}$ We have also studied barium strontium titanate $\left(\mathrm{Ba}_{0.8} \mathrm{Sr}_{0.2} \mathrm{TiO}_{3}\right.$ or BST) which is a well-known ferroelectric at room temperature (when $\mathrm{Ba} / \mathrm{Sr}$ ratio is above o.7/o.3) and has remarkable optical and dielectric properties. Thus, it is suitable for applications such as non-linear optics, infrared detectors, thermal imaging, microwave dielectrics or capacitors. ${ }^{40-42}$ Finally, lanthanum strontium manganite $\left(\mathrm{La}_{0.7} \mathrm{Sr}_{0.3} \mathrm{MnO}_{3}\right.$ or LSMO) is an oxide material with physical properties such as room temperature ferromagnetism and metallic conductivity or colossal magnetoresistance that presents resistive switching and it has recently been discovered as an interesting candidate for non-volatile resistive random access memories (NVRAM). ${ }^{43-46}$

We have performed a detailed characterization of the oxide epitaxial crystallization by employing a quantification procedure that involves two-dimensional X-ray diffraction (2D-XRD) measurements. The physical properties of the films are also evaluated, and the results are correlated with equivalent samples produced by conventional thermal treatments. Finally, the thermal evolution inside the oxide heterostructures during irradiation is evaluated by finite element simulations. These findings strengthen our experimental results and provide a better understanding of laser photoinduced crystallization of functional oxide thin films.

\section{EXPERIMENTAL SECTION}

2.1 Material preparation. The oxide thin films investigated in this work were deposited by the chemical solution deposition (CSD) method on (oo1)-oriented $\mathrm{Y}_{2} \mathrm{O}_{3}: \mathrm{ZrO}_{2}$ (YSZ), $\mathrm{LaAlO}_{3}$ (LAO) and $\mathrm{SrTiO}_{3}$ (STO) single crystal substrates (Crystec Gmbh) of $5 \times 5 \mathrm{~mm}^{2}$ and 0.5 $\mathrm{mm}$ in thickness, as it will be described next. Firstly, $\mathrm{Ce}_{\mathrm{o} .9} \mathrm{Zr}_{\mathrm{o} .1} \mathrm{O}_{2-\mathrm{y}}(\mathrm{CZO})$ precursor solutions with a concentration of $0.25 \mathrm{M}$ were prepared by adding cerium (III) and zirconium (IV) acetylacetonate salts (Sigma-Aldrich) in propionic acid and stirring the mixture at 50 으 for 30 min. ${ }^{33}$ The solution was then spun at $6000 \mathrm{rpm}$ for $2 \mathrm{~min}$ onto thoroughly cleaned (oo1) YSZ substrates. The metalorganic films were heated at $300{ }^{\circ} \mathrm{C}$ for $30 \mathrm{~min}$ with a tubular furnace to fully decompose the organic material obtaining a nanocrystalline CZO film before the laser irradiation. ${ }^{47}$ Secondly, stoichiometric $0.2 \mathrm{M} \mathrm{LaNiO}_{3}$ (LNO) solutions were synthesized from lanthanum (III) nitrate and nickel (II) acetate salts (Sigma-Aldrich) diluted in 2-methoxyethanol and refluxed at $125{ }^{\circ} \mathrm{C}$ for a few hours. ${ }^{34}$ Deposition by spin coating on (oo1) STO substrates was done with the same conditions as for CZO. Full removal of organic residues for the metalorganic LNO precursor films was achieved by thermal annealing at $350^{\circ} \mathrm{C}$ for $30 \mathrm{~min}$ using a tubular furnace. Thirdly, $\mathrm{Ba}_{0.8} \mathrm{Sr}_{0.2} \mathrm{TiO}_{3}$ (BST) precursor solutions with a $0.3 \mathrm{M}$ concentration were prepared by diluting barium (II) and strontium (II) acetate salts (Sigma-Aldrich) in propionic acid for $3 \mathrm{~h}$, and then adding titanium (IV) isopropoxide. ${ }^{34}$ Acetylacetone was used as stabilizing agent. BST solutions were spin-coated at 6000 rpm for 2 min on (oo1) ${ }^{\text {CSD }}$ LNO / (oo1) LAO buffered substrates, and fully decomposed at $450{ }^{\circ} \mathrm{C}$ for $10 \mathrm{~min}$. The (oo1) LNO epitaxial buffer layers with thicknesses of $\sim 25 \mathrm{~nm}$ were produced by thermal annealing of metalorganic films at $700{ }^{\circ} \mathrm{C}, 10^{\circ}{ }^{\circ} \mathrm{C} \min ^{-1}$ for 1 $\mathrm{h}$ in oxygen. Finally, the procedure used to synthesize 0.3 $\mathrm{M} \mathrm{La}_{0.7} \mathrm{Sr}_{0.3} \mathrm{MnO}_{3}$ (LSMO) precursor solutions consisted of mixing lanthanum (III), strontium (II) and manganese (II) acetates in acetic acid, and stirring the mixture at $50{ }^{\circ} \mathrm{C}$ for 10 min. ${ }^{48}$ Again, the solution was spun at the conditions reported before onto (oo1) STO substrates. The metalorganic films were then heated up to $300{ }^{\circ} \mathrm{C}$ and 
held there for 30 min to obtain a fully decomposed amorphous layer. No traces of organic residues or carbon where detected by FTIR and EELS spectroscopies. ${ }^{15,}$ 47, 49

Pulsed laser annealing (PLA) of the amorphous/nanocrystalline oxide films was done with a Brilliant Nd:YAG laser (Quantel) working at a wavelength of $266 \mathrm{~nm}$, and sending pulses that last $3 \mathrm{~ns}$ at a repetition rate of $10 \mathrm{~Hz}$. The spatial distribution of the laser beam was almost a Gaussian of approximately $6 \mathrm{~mm}$ in diameter. Thus, the laser fluence, defined as the pulse energy per unit area, radially decreased from its maximum value at the beam center, being twice the average fluence (i.e. the pulse energy divided by the beam area). Inhomogeneous crystallization that could result from the Gaussian beam was reduced by irradiating regularly spaced locations separated $1 \mathrm{~mm}$ from each other, and providing a beam overlapping of $\sim 80 \%$, as reported previously. ${ }^{33}, 34,49$ We estimated that the overall accumulated pulses/site due to overlapping was around 13 times the one applied at each location. Films were irradiated in air at selected laser fluences by tuning the incoming laser energy. The substrate base temperature during irradiation was fixed for all experiments at $400{ }^{\circ} \mathrm{C}$ with a precision of $\pm 1{ }^{\circ} \mathrm{C}$ using a PID controlled heater (Watlow Ultramic 6oo).

2.2 Characterization. Atomic force microscopy (AFM) was used to characterize films morphology with an Agilent 5100 system operating in intermittent contact mode. The topographic measurements obtained were analyzed with the MountainsMap 7.0 software (Digital Surf). X-ray diffraction (XRD) $\theta-2 \theta$ analyses were conducted to evaluate the crystallographic structure of samples. Also, a quantitative analysis of the epitaxial fraction was carried out using a procedure based on two-dimensional (2D) XRD measurements, detailed later., 23, 49 Pole figure measurements were conducted by integrating $3602 \mathrm{D}$ XRD frames collected at steps of $\Delta \phi=1^{\circ}$ for 20 s each frame. Data acquisition was done with a Rigaku Rotaflex RU-20oBV diffractometer and a GADDS system from Bruker equipped with a $2 \mathrm{D}$ detector. High resolution transmission electron microscopy (HRTEM) investigations were employed to complete our crystallization studies. FEI Tecnai F2o and JEOL J2010F microscopes operated at $200 \mathrm{kV}$, with lateral resolutions of $0.14 \mathrm{~nm}$, provided high resolution images of cross-sectional specimens that were prepared by mechanical polishing and ion milling. In addition, we characterized different physical properties of the samples. We measured the electrical resistivity of LNO films using a physical properties measurement system (PPMS) from Quantum Design Inc., setting the electrical contacts in a four-probe configuration and following the van der Pauw method..$^{5}$ Magnetization measurements of LSMO films were carried out with a commercial MPMS XL-7T superconducting quantum interference device (SQUID) DC-magnetometer (Quantum Design, Inc.) with the applied magnetic field parallel to the substrate plane. The optical properties of fully decomposed films such as reflectance and transmittance (Figure $\mathrm{S}_{1}$ ) were measured with a Varian Cary 500 UV-Vis-NIR spectrophotometer. The Denton method was then used to calculate the refractive index $(n)$, extinction coefficient $(\kappa)$, absorption coefficient $\left(\alpha=4 \pi \kappa \lambda^{-1}\right)$ and optical penetration depth $\left(l_{\alpha}=\alpha^{-1}\right)$, at each wavelength $\lambda . .^{51}$ Finally, we simulated the thermal behaviour induced in the oxide heterostructures by laser annealing. COMSOL 4.4 Multiphysics software was employed to solve the transient heat equation with the finite element method. Additional details on the simulation procedure have already been described in the Supporting Information and in Refs. 23, 33, 34, 49. Further optical parameters, as well as different thermophysical properties of films and substrates used in the calculations have already been reported in Refs. 10, 33, 34, 47, 52-66 and are summarized in the Supporting Information (Table $\mathrm{S} 1$ ).

\section{RESULTS AND DISCUSSION}

3.1 Laser crystallization of oxide films. Two dominant effects are usually considered during laser irradiation, namely photochemical and photothermal interactions. On the one hand, photochemical effects involve the direct breaking of chemical bonds which occur typically when the laser photon energy is larger than the energy needed to dissociate chemical bonds. These mechanisms have interaction times shorter than picoseconds. On the other hand, photothermal interactions, much longer in duration $\left(10^{-3}-10^{-1} \mathrm{~ns}\right)$, are caused by the thermalization of excited electrons. The amorphous/nanocrystalline films produced after the pyrolysis of metalorganic precursors are fully decomposed since no presence of organic residues or C-impurities are detected by FTIR spectroscopy. Then, one can assume that these films mostly consist of metal-oxygen bonds; i.e. Ce-O, $\mathrm{Zr}-\mathrm{O}$, La-O, Ni-O, Ba-O, $\mathrm{Sr}-\mathrm{O}$, Ti-O, Mn-O; with dissociation energies ranging from 392 to $799 \mathrm{~kJ} \mathrm{~mol}^{-1}$ (4.1 to $8.3 \mathrm{eV} /$ bond). ${ }^{67}$ Since the laser photons have an energy of $\sim 4.7 \mathrm{eV}$ at $266 \mathrm{~nm}$, we can expect the presence of photochemical interactions in the oxide layers investigated. Nevertheless, we suspect that they will not be as significant as photothermal ones because the laser pulse duration of $3 \mathrm{~ns}$ is much longer than electron thermalization times. It is also worth mentioning that any undetected organic bonds that could survive the pyrolysis treatment, mainly $\mathrm{C}-\mathrm{C}, \mathrm{C}-\mathrm{O}$ and $\mathrm{C}-\mathrm{H}$ with dissociation energies of 3.6-4.3 eV/bond, ${ }^{15}$ would be photochemically/photothermally removed during the initial stages of irradiation.

The heat produced during irradiation is partially determined by the amount of laser photons absorbed in the film, which is expressed on the optical penetration depth $\left(l_{\alpha}=\alpha^{-1}\right)$. The values of $l_{\alpha}$ at $\lambda=266 \mathrm{~nm}$, extracted from Figure $\mathrm{S} 1$, are approximately 32, 79, 48 and $42 \mathrm{~nm}$ for CZO, LNO, BST and LSMO pyrolyzed films, respectively, while their thicknesses determined from X-ray reflectometry (XRR) measurements (Figure S2) are 26, 39, 43 and $45 \mathrm{~nm}$. Then, it can be estimated from the Beer-Lambert law that a 54, 40, 57 and $66 \%$ of the incoming radiation intensity is absorbed by CZO, LNO, BST and LSMO pyrolyzed 
films. The remaining radiation is transmitted and absorbed by the substrates which will have an important contribution to the overall heating process. The photothermally-generated heat produced from the radiation absorbed, as well as the laser annealing conditions is assessed by solving the heat equation with numerical simulations. Figure ra shows the simulated temperature profiles for 40-nanometer thick LNO films on STO substrates irradiated with a single laser pulse at fluences of 20,30 and $40 \mathrm{~mJ} \mathrm{~cm}^{-2}$ and a substrate temperature of 400 ${ }^{\circ} \mathrm{C}$. The use of a substrate base temperature has been demonstrated advantageous to decrease film RMS roughness, to improve film surface homogeneity and degree of crystallization, and prevent or reduce crack formation. ${ }^{23}$, 33, 49 These phenomena have been linked to the boost in the maximum temperatures reached, the decrease of the temperature gradient between the film surface and the interface with the substrate, but also due to longer heating times at temperatures promoting crystallization, i.e. above $600{ }^{\circ} \mathrm{C}$, as shown in Figure $\mathrm{S}_{3}$. Equivalent simulations for CZO on YSZ, BST on LNO/LAO and LSMO on STO can be found in the Supporting Information (Figure $\mathrm{S}_{4}$ ). It can be seen that very fast thermal cycles lasting from tens to hundreds of nanoseconds are generated in the films with each laser pulse. The maximum temperatures reached at the film surfaces range from $1150-1900{ }^{\circ} \mathrm{C}$ for $\mathrm{CZO}, 750-1150^{\circ} \mathrm{C}$ for $\mathrm{LNO}, 800-1200^{\circ} \mathrm{C}$ for BST, and

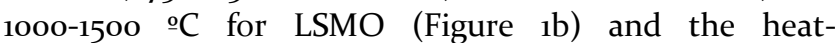
ing/cooling rates achieve up to $\sim 10^{10} \circ \mathrm{C} \mathrm{s}^{-1}$. The fast laser treatments induce large temperature differences from 50 to $400{ }^{\circ} \mathrm{C}$ between the film surface and film/substrate interface. These differences lead to temperature gradients in the films over $10^{9}{ }^{\circ} \mathrm{C} \mathrm{m}^{-1}$. The effective heating time for a single pulse $t_{\text {eff }}$ is used to estimate the effective duration for photothermal laser heating and it has been defined as the time duration the film is above $600{ }^{\circ} \mathrm{C}$ (assumed as the minimum temperature required for crystallization). Figure $\mathrm{S}_{5}$ shows that the values of $t_{\text {eff }}$ for a single laser pulse increase with the laser fluence and greatly depend on the system due

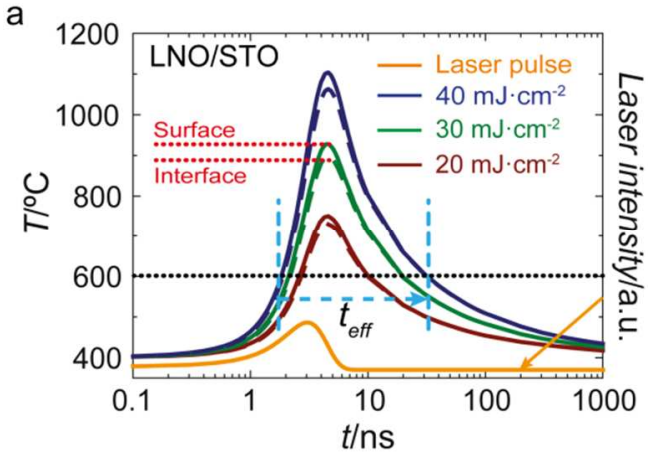

b

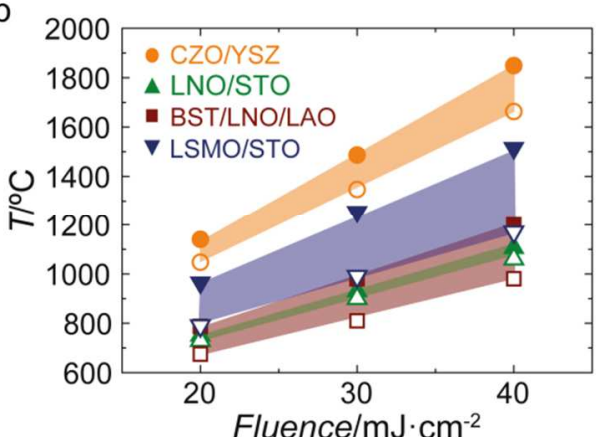

Figure 1. Simulations of laser photo-induced thermal effects on films with thicknesses of $40 \mathrm{~nm}$. (a) Temporal evolution of the temperatures reached at the LNO film surface and LNO/STO interface after irradiation at 20,30 and $40 \mathrm{~mJ} \mathrm{~cm}$ and with the substrate at $400{ }^{\circ} \mathrm{C}$. Solid and dashed lines indicate the temperature at film surface and film/substrate interface, respectively. (b) Maximum temperature evolution with the laser fluence of CZO/YSZ, LNO/STO, BST/LNO/LAO and LSMO/STO heterostructures. Filled and open symbols indicate, respectively, the maximum temperature at the film surface and film/substrate interface.

to the different optical and thermophysical parameters of the different oxide components. For instance, the effective heating time for $\mathrm{CZO}$ is $\sim 5$ times longer than for BST

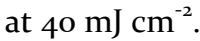

Pulsed laser annealing is performed on CZO, LNO, BST and LSMO pyrolyzed films with an $80 \%$ of beam overlapping and a substrate temperature of $400^{\circ} \mathrm{C}$, as mentioned before. Laser fluences of $30 \mathrm{~mJ} \mathrm{~cm} \mathrm{~cm}^{-2}$ (LNO and LSMO) and $40 \mathrm{~mJ} \mathrm{\textrm {cm } ^ { - 2 }}$ (CZO and BST) are carefully selected to achieve solid-state laser crystallization, i.e. without exceeding the melting temperature of each oxide (Table $\mathrm{S}_{1}$ ). The applied number of pulses per site ranges from 1000 to 20000 pulses/site. The surface morphology of pyrolyzed oxide films is very flat with RMS roughnesses of 0.3-0.4 $\mathrm{nm}$ (Figure S6). After laser irradiation, the morphology of $\mathrm{CZO}$ films present grains of few tens of nanometers in size that grouped in domains up to 100-200 nm after accumulating a large number of pulses. Their RMS roughness after irradiation is kept constant with the number of pulses at $0.7-0.8 \mathrm{~nm}$. In contrast, LNO, BST and LSMO films consist of periodical structures, also known as ripples, with sizes of $200-300 \mathrm{~nm}$. The formation of these structures is a widely observed effect on laser irradiation of surface materials, which origin is ascribed to complex 
scattering and interference mechanisms ${ }^{10,68,69}$ that has not been assessed in this work. The film roughnesses for LNO, BST and LSMO after applying 2500 pulses/site are 2.3, 8.5 and $2.9 \mathrm{~nm}$, respectively, and experienced a notable increase with the number of pulses up to $4.8,13.9$ and $4.0 \mathrm{~nm}$ (20000 pulses/site) as ripples developed (Figure S6). Typically, thermally annealed films have much more flat surfaces, ${ }^{70,71}$ and thus, such rough morphology will have an influence on the functional properties of films as it will be detailed later.

Figure 2 displays the XRD diffractograms of $\mathrm{CZO} / \mathrm{YSZ}$, LNO/STO, BST/LNO/LAO and LSMO/STO heterostructures irradiated at the aforementioned experimental conditions. Firstly, we identify the (002) peaks of YSZ, STO and LAO substrates located at $35.0^{\circ}, 46.5^{\circ}$ and $48.0^{\circ}$, respectively, and weak peaks associated to their $\mathrm{K}_{\beta}$ signal at $31.4^{\circ}, 41.8^{\circ}$ and $43.1^{\circ}$. The (oo2) LNO reflection of the LNO buffer layer is also seen in the BST/LNO/LAO system. Regarding laser annealed films, we detect the (oo2) epitaxial reflections of $\mathrm{CZO}$ at $33.4^{\circ}$, LNO at $47.3^{\circ}$, BST at $45.9^{\circ}$ and LSMO at $46.9^{\circ}$. The intensity of these epitaxial peaks increases with the number of pulses. A very weak polycrystalline peak is identified at $28.8^{\circ}$ for $\mathrm{CZO} / \mathrm{YSZ}$ heterostructures, i.e. (111) $\mathrm{CZO}$, after accumulating 1000 pulses/site that seems to disappear when more pulses are applied (Figure 2a). No apparent peaks associated to polycrystalline material are observed for the other oxide systems. Therefore, these results indicate that we are able to induce epitaxial crystallization from the initial amorphous/nanocrystalline material by laser annealing.

A more detailed study of CZO and BST films grown on YSZ and LNO/LAO, respectively, conducted by HRTEM is presented in Figure 3. Both samples are irradiated at 40

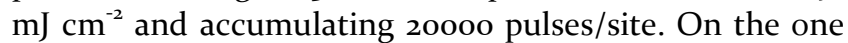
hand, Figure za shows that the region close to the $\mathrm{CZO} / \mathrm{YSZ}$ interface grows epitaxially. Specifically, we estimate that the epitaxial thickness is around a $40-50 \%$ of the whole CZO film. The remaining film consists of polycrystalline grains, as inferred from the power spectrum of the image. Additionally, the epitaxial region of the CZO film seems fully relaxed on top of the YSZ substrate with a lattice parameter equivalent to the bulk $\left(\mathrm{a}_{\text {CZO,exp }}=\mathrm{a}_{\text {CZO,bulk }}=5.385 \AA, \mathrm{a}_{\text {YSZ,bulk }}=5.143 \AA\right.$ ). On the other hand, Figure $3 \mathrm{~b}$ shows that the BST film grows completely epitaxial on the (oo1) LNO buffer layer, as evidenced by the fast Fourier transform. These studies also reveal that the epitaxial LNO buffer layer is fully strained on top of the LAO substrate $\left(\mathrm{a}_{\mathrm{LNO}, \exp }=\mathrm{a}_{\mathrm{LAO} \text {,bulk }}=3.788 \AA \AA \quad \mathrm{a}_{\mathrm{L}}\right.$ No,bulk $=3.850 \AA$ ). Consequently, the BST lattice parameter is also compressed with respect to its bulk value $\left(\mathrm{a}_{\mathrm{BST}, \mathrm{bulk}}=3.993 \AA\right)$. In this case, the compression is of $-2.7 \%$ $\left(\mathrm{a}_{\mathrm{BST}, \exp }=3.884 \AA\right)$ indicating that the BST film is only partially strained.

The local nature of TEM required a more general method to evaluate the amount of epitaxial material in the films. In particular, we measure the epitaxial fraction following a procedure based on $2 \mathrm{D}$-XRD experiments already described in Refs. ${ }^{4}$ 23, 49. Basically, it consists of performing a measurement at fixed $\phi, 2 \theta, \chi$ and $\omega$ angles with a $2 \mathrm{D}$ detector to acquire multiple crystallite orientations of a film simultaneously. The reflections selected to perform the analyses are the (o11) orientation for LNO, BST and LSMO, and the (022) orientation for CZO which correspond to values of $\omega \sim 15^{\circ}, \chi \sim 45^{\circ}$ and $2 \theta \sim 47.73^{\circ}(\mathrm{CZO})$,

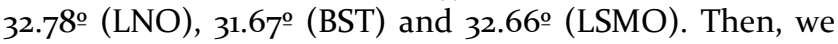
quantify the amount of (oo1) film crystallites aligned with the (ool) substrate orientation $\left(I_{\text {epitaxial }}\right)$ with respect to other film orientations (polycrystalline material $-I_{\text {random }}$ ) employing the following expression:

$$
\frac{I_{\text {random }}}{I_{\text {epitaxial }}}=\frac{4 \pi(360 / \Delta \chi) I_{\text {ring }}^{\text {exp }}}{8 I_{\text {epi }}^{\text {exp }}}
$$




\section{a}
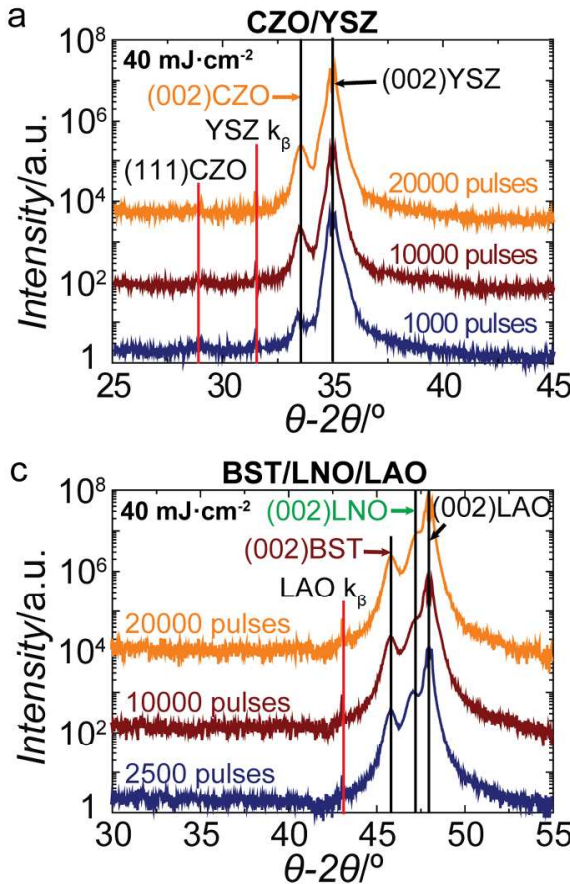
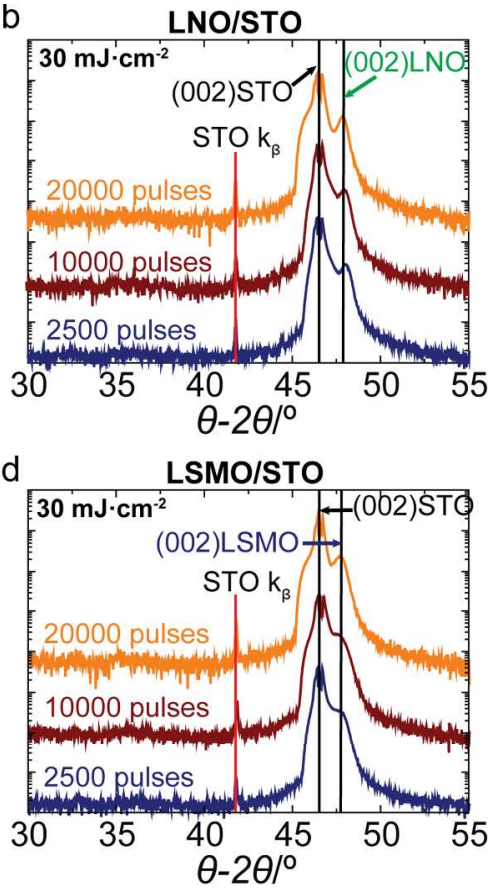

Figure 2. $\theta-2 \theta$ XRD measurements of laser-crystallized films: (a) CZO on YSZ, (b) LNO on STO, (c) BST on LNO/LAO and (d)

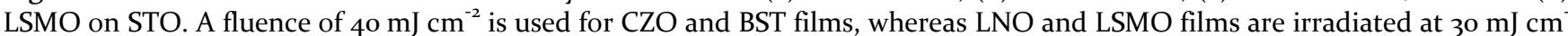
${ }^{2}$. The number of accumulated pulses/site ranges from 1000 to 20000 for CZO films, and from 2500 to 20000 pulses for LNO, BST and LSMO films as indicated.
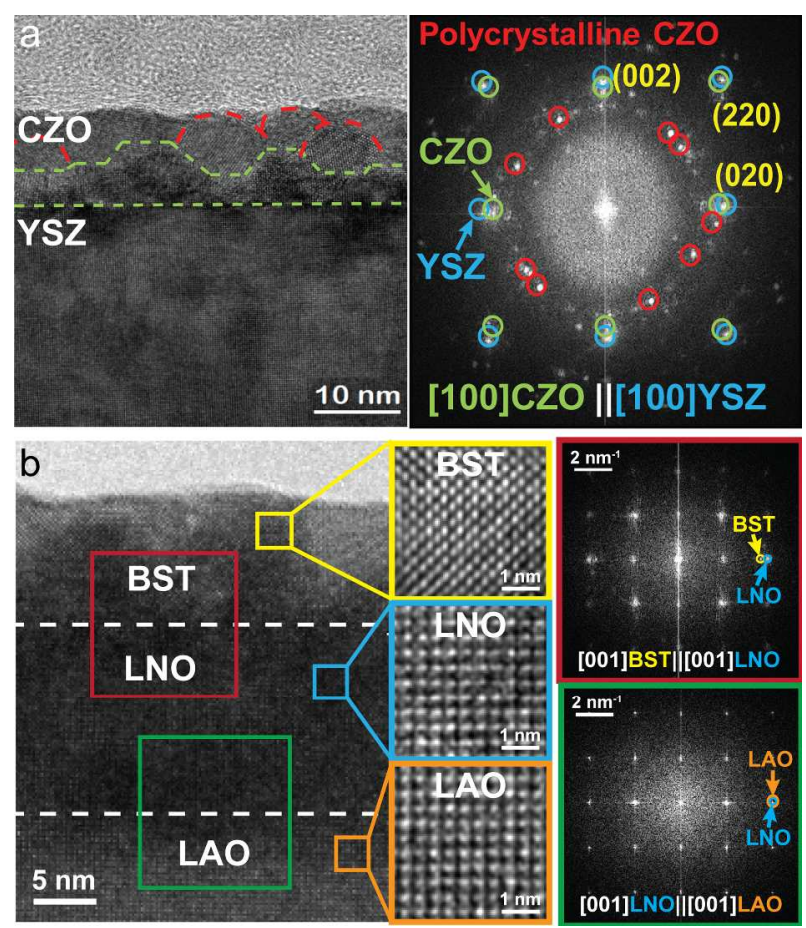

Figure 3. HRTEM characterization of: (a) CZO on YSZ, and

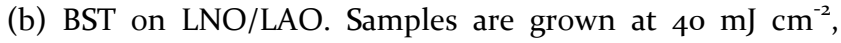
applying 20000 pulses/site. Colored frames correspond to the different areas investigated.

where $I_{e p i}^{e x p}$ and $I_{\text {ring }}^{e x p}$ correspond to the diffracted intensities of the epitaxially textured and polycrystalline ring phases, and $\Delta \chi$ is the angular range accounting for misoriented crystallites. Percent values are calculated considering that $I_{\text {random }}+I_{\text {epitaxial }}=100$ (\%). Figure $\mathrm{S}_{7}$ illustrates the raw data used in the epitaxial fraction quantification of $\mathrm{CZO} / \mathrm{YSZ}, \mathrm{LNO} / \mathrm{STO}, \mathrm{BST} / \mathrm{LNO} / \mathrm{LAO}$ and LSMO/STO heterostructures after laser irradiation. The epitaxial component of films and substrates is depicted as a central "spot", whereas the ring corresponds to the polycrystalline material fraction. No secondary phases are found. Figure 4a displays the quantification of the epitaxial fraction from $2 \mathrm{D}$-XRD measurements in Figure $\mathrm{S}_{7}$ for laser annealed CZO, LNO, BST and LSMO films as a function of the overall effective heating time which is calculated by multiplying the number of accumulated pulses by the effective heating time of a single pulse. The beam overlapping is also considered in the calculation. Since the amount of material available to transform is fixed by the solution deposition, the data presented is fitted assuming that the epitaxial transformation follows a self-limited growth behavior similar to that reported for grain growth by Rupp et al. ${ }^{72,73}$ and described in the Supporting Information.

As we hinted before, the degree of epitaxy increases with the effective heating time, i.e. as more pulses/site are accumulated. In particular, the epitaxial fraction for CZO films rises from $\sim 20 \%$ at $0.4 \mathrm{~ms}$ (1000 pulses/site) to $50-$ $55 \%$ at $7.2 \mathrm{~ms}$ (20000 pulses/site). It is worth noticing that these values are quite similar to the estimation made from the epitaxial film thickness observed by HRTEM (Figure 3a). We predict from data fitting that it would take around 140000 pulses/site $(\sim 53 \mathrm{~ms})$ to obtain a completely epitaxial CZO film. In contrast, full epitaxial transfor- 
mation of LNO, BST and LSMO films is obtained after few milliseconds, i.e. between 1.3 and $2.4 \mathrm{~ms}$, which we achieve experimentally by accumulating between 1000 and 20000 pulses/site. These results are around one order of magnitude faster than for CZO. Figure S8 presents $2 \mathrm{D}$ XRD (022)-centered pole figure measurements for $\mathrm{CZO}$, LNO, BST and LSMO films annealed by laser at fluences of $30-40 \mathrm{~mJ} \mathrm{~cm} \mathrm{~cm}^{-2}$ and 20000 pulses/site. We observe that $\mathrm{CZO}$ has four poles at $\chi=45^{\circ}$ corresponding to the (oo2) orientation characteristic of epitaxial growth, but also we detect other signals that can be attributed to the presence of random grains in the film. On the other hand, LNO, BST and LSMO films only show the four poles at $\chi=45^{\circ}$ which demonstrates their full epitaxial growth.

We can also extract the epitaxial growth rate evolution with the effective time (Figure 4 b) by deriving the fitted curves in Figure 4a with respect to the effective heating time and multiplying by the final film thickness i.e. around 20, 25, 35 and $30 \mathrm{~nm}$ for CZO, LNO, BST and LSMO, respectively. Interestingly, we see that the epitaxial growth rates have an initial value that decreases with the effective heating time as the epitaxial growth proceeds. This suggests that the driving force towards epitaxial crystallization is higher at the beginning and it is reduced as less polycrystalline material is able to transform. The initial values for the epitaxial growth rates, presented in Figure S9a, are approximately $2.5 \times 10^{3} \mathrm{~nm} \mathrm{~s}^{-1}$ for $\mathrm{CZO}$, whereas LNO, BST and LSMO films have epitaxial growth rates which are almost two orders of magnitude higher, i.e. $7.5 \times 10^{4}, 7.0 \times 10^{4}$ and $9.8 \times 10^{4} \mathrm{~nm} \mathrm{~s}^{-1}$, respectively. The different optical and thermal response of films and substrates, as well as the probable distinct contribution of photochemical interactions could explain this variation in growth rates. Despite that, a large difference of 4-6 orders of magnitude is detected when we compare these values with the epitaxial growth rate of thermally treated films which are between 0.01 and $0.1 \mathrm{~nm} \mathrm{~s}^{-1} .33$ The formation of a crystalline phase from amorphous/nanocrystalline material is driven by a decrease in the Gibbs free energy, but also by a reduction in the surface to volume ratio of polycrystalline grains. In addition, the conversion from polycrystalline material to epitaxial grains is achieved by grain boundary reconstruction typically involving a thermallyactivated diffusion process. We calculate the diffusion coefficients of the epitaxial laser growth from Figure $4 \mathrm{a}$ applying the aforementioned self-limited growth model, ${ }^{33}$, ${ }^{73}$ described in the Supporting Information. As observed in Figure S9b, the effective epitaxial diffusion coefficients are approximately $1.3 \times 10^{-14}, 5.2 \times 10^{-13}, 6.1 \times 10^{-13}$ and $7.5 \times 10^{-13}$ $\mathrm{m}^{2} \mathrm{~s}^{-1}$ for CZO/YSZ, LNO/STO, BST/LNO/LAO and LSMO/STO heterostructures, respectively. The diffusion coefficient of CZO/YSZ is around one order of magnitude smaller than the other oxide systems studied, whereas these values are around 5-6 orders of magnitude larger than those of thermal treatments $\left(\sim 10^{-19}-10^{-18} \mathrm{~m}^{2} \mathrm{~s}^{-1}\right) .^{33}$ Although laser treatments usually develop higher temperatures, i.e. thermal treatments reach up to $1000 \stackrel{\circ}{C}$, as shown in Figure 1, it has been previously demonstrated that the temperature differences between thermal and laser treatments are insufficient to induce such variation of diffusion coefficients between thermal and laser annealing. ${ }^{33}$ However, external driving forces such as temperature gradients, electric fields, etc., could highly influence atomic diffusion. ${ }^{74}$ In particular, the contribution of temperature gradients on atomic diffusion for thermal treatments is insignificant (constant temperature in overall system) compared to laser irradiation where temperature gradients as high as $10^{9}{ }^{\circ} \mathrm{C} \mathrm{m}^{-1}$ can be reached. Thus, it would be feasible for the large temperature gradients to act as intense driving forces towards the enhancement of the atomic diffusion for epitaxial growth. ${ }^{33}$

The Johnson-Mehl-Avrami-Kolmogorov (JMAK) theory describes the volume fraction of the crystallized phase, $X$, in isothermal conditions, and assuming that nucleation and growth rates are time independent with a phenomenological equation ${ }^{75-78}$ :
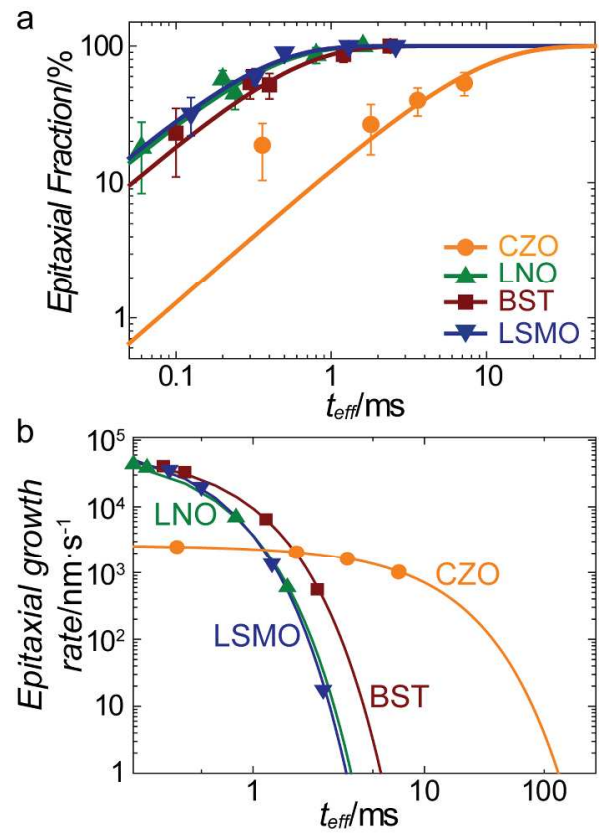

Figure 4. (a) Evolution of the epitaxial fraction and data fitting associated with CZO, LNO, BST and LSMO laser irradiated films. (b) Dependence of the epitaxial growth rate for the oxides indicated with the effective heating time. These values are obtained by transforming the epitaxial fraction to thickness using the values reported in the manuscript.

$X=1-\exp \left[-(K t)^{m+1}\right]$

where $m+1$ is the Avrami exponent, and $K$ is the rate constant per mole given by:

$K=K_{0} \exp \left(-Q / k_{B} T\right)$

where $Q$ is the activation energy, $k_{B}$ is the Boltzmann constant, $T$ is the temperature, and $K_{o}$ is the attempt frequency $\left(\sim 10^{12} \mathrm{~s}^{-1} \text { mole }^{-1} \text { for laser annealing }\right)^{77}$. Farjas et al. modified the JMAK equation to account for nonisothermal situations such as pulsed laser annealing ${ }^{79}$ :

$\frac{d X}{d t}=(m+1) \cdot C \cdot K \cdot(1-X) \cdot[-\ln (1-X)]^{m / m+1}$ 
where $C$ is a constant that depends on $m$, and the activation energies for nucleation and growth $\left(E_{N}\right.$ and $\left.E_{G}\right)$. The activation energies $Q\left[=\left(E_{N}+m E_{G}\right) /(m+1)\right]$ for the different laser irradiated films can be extracted by combining Equation 3 and 4 . In our calculations, we assume that $C=1$ $\left(E_{N}=E_{G}\right), m=2,3(2 \mathrm{D} \text { and } 3 \mathrm{D} \text { growth })^{77,80}$ and average irradiation temperatures of $1193,791,839$ and $867^{\circ} \mathrm{C}$ for CZO, LNO, BST and LSMO, respectively. These average temperature values have been extracted from Figure 1a and $\mathrm{S}_{4}$ for temperatures above $60^{\circ}{ }^{\circ} \mathrm{C}$. The calculated activation energies $Q$ are 3.0-3.2 eV (CZO), 1.9-2.1 eV (LNO), 2.0-2.2 eV (BST) and 2.1-2.2 eV (LSMO). These values seem equivalent to those determined for some solgel derived oxides, i.e. 2.4 eV for YSZ, 3.0-3.8 eV for mullite. ${ }^{81,82}$ These values indicate that the thermal energy required for the activation of nucleation and crystallization is quite high. In addition, they are in accordance with the results of diffusion coefficients calculated before. Typically, crystallization processes controlled by bulk diffusion have energy values of few eV, while energies in the range of 0.1-1 eV are usually indicative of surface or grain boundary diffusion mechanisms controlling crystallization. ${ }^{78}$ Activation energies around $4.7 \mathrm{eV}$ have been reported for $\mathrm{Gd}$-doped $\mathrm{CeO}_{2}$ films, and between 5.1 and $6.8 \mathrm{eV}$ for YSZ films grown by PLD. ${ }^{78,83}$ Both works attributed such high activation energies to bulk diffusion. In contrast, activation energies as low as $1.3 \mathrm{eV}$ have been attributed to grain boundary diffusion in CGO films by Rupp et $a .^{72}$ It seems then that bulk diffusion is the main mechanism controlling film growth. Despite that, grain boundary diffusion may also be involved in the crystallization of our films. The contribution of volume diffusion should be larger on the crystallization of CZO films as compared to LNO, BST and LSMO films due to the larger activation energies.

3.2 Functional properties of laser annealed films. The viability of pulsed laser annealing as a technique used in the production of epitaxial oxide thin films is also tested by measuring their functional properties, and comparing them with equivalent epitaxial films obtained by thermal treatments. Specifically, we measure the electrical resistivity of LNO films grown on STO by PLA at $30 \mathrm{~mJ}$ $\mathrm{cm}^{-2}$ with a substrate temperature of $400 \stackrel{\circ}{ } \mathrm{C}$ and applying 20000 pulses/site in air (Figure 5 ). The results are compared with a thermally annealed film produced with a tubular furnace at $700{ }^{\circ} \mathrm{C}, 10{ }^{\circ} \mathrm{C} \mathrm{min}^{-1}$ for $1 \mathrm{~h}$ in $\mathrm{O}_{2}$. Both LNO films show good metallic response with similar values to those reported in the literature. ${ }^{84},{ }^{85}$ Despite that, resistivity is around one order of magnitude higher for the laser treated film than for the thermally annealed one, which is close to values reported for polycrystalline LNO films. ${ }^{86,87}$ Notice that the laser irradiated sample has a rougher morphology due to the presence of ripples. We may also expect that laser irradiated LNO films present a larger amount of microstructural defects accumulated at the low angle grain boundaries as compared to thermally annealed ones which would have these defects healed. ${ }^{88}$
These microstructural defects accumulated in the laser annealed samples could cause an increase of the structural disorder and so of the electrical resistivity. ${ }^{89}$ It should be emphasized that the effective heating time is orders of magnitude shorter for laser annealing ( $0.4 \mathrm{~ms}$ ) compared to thermal treatments $(1 \mathrm{~h})$. Thus, further irradiation providing higher crystallinity, i.e. larger grain sizes, and grain boundary healing should lead to lower resistivity values in the range of thermal treatments.

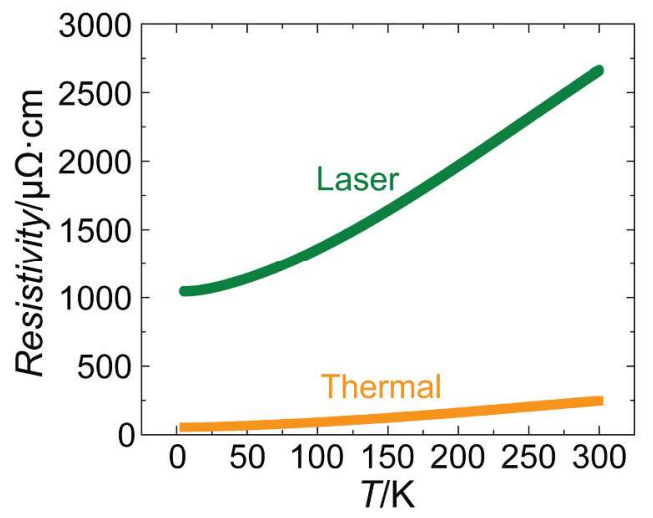

Figure 5. Temperature dependence of the electrical resistivity measured for LNO films on STO. Films are grown by laser

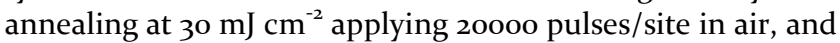
by thermal annealing at $700{ }^{\circ} \mathrm{C}, 10^{\circ} \mathrm{C} \mathrm{min}^{-1}$ for $1 \mathrm{~h}$ in $\mathrm{O}_{2}$.

In the case of BST on LNO/LAO, the local ferroelectric performance has been evaluated previously by conducting PFM measurements. ${ }^{34}$ The study reveals similar PFM behavior between laser and thermally annealed samples. However, it should be noticed that the presence of ferroelectricity cannot only be inferred from PFM measurements since electrostatically-induced charge migration can be induced by the AFM tip, ${ }^{\circ}$ and thus, additional measurements should be conducted to confirm the presence of ferroelectricity.

Finally, we investigate the magnetic properties of LSMO films on STO (Figure 6). In this case, the samples exam-

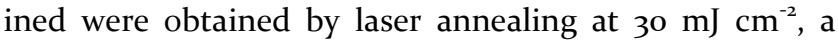
substrate temperature of $400{ }^{\circ} \mathrm{C}$, and 2500 and 1000 pulses/site. Irradiation was done in air as mentioned before. These films are compared with two samples prepared by CSD and thermal annealing at $100{ }^{\circ} \mathrm{C}, 3^{\circ} \mathrm{C} \mathrm{min}^{-1}$ for $1 \mathrm{~h}$ in air and oxygen, respectively. We measure the magnetization $(M)$ dependence with temperature $(T)$ at a constant magnetic field of $5 \mathrm{kOe}$, and its dependence with the magnetic field $(H)$ at $35 \mathrm{~K}$ using a SQUID magnetometer. Figure 6a shows that the films grown by laser annealing after accumulating 2500 and 10000 pulses/site have a saturation magnetization $\left(M_{s}\right)$ of 340 and $515 \mathrm{kA} \mathrm{m}$ ${ }^{1}$, respectively. This increase is due to the improvement of crystallization. Instead, the film prepared by thermal annealing in $\mathrm{O}_{2}$ has a saturation magnetization $\left(M_{s}\right)$ identical to the bulk value $\left(\sim 590 \mathrm{kA} \mathrm{m}^{-1}\right),{ }^{91}$ whereas the film produced at the same annealing conditions in air presents a $M_{s}$ somewhat smaller $\left(\sim 545 \mathrm{kA} \mathrm{m}^{-1}\right)$. The lower value of magnetization for laser treated films with a large number of accumulated pulses as compared to the thermal an- 
nealed ones could be mostly explained by the atmosphere used during irradiation, as well as a small contribution of the presumably lower degree of crystallization, leading to smaller crystallite sizes as compared to thermal treatments. We also see an increase in saturation magnetization with the number of pulses, i.e. the effective heating time, which is associated to a boost of the epitaxial fraction (Figure 4a). The sample irradiated with 2500 pulses/site $\left(t_{\text {eff }} \sim 0.1 \mathrm{~ms}\right)$ has an epitaxial fraction of $50-60 \%$, while full epitaxy is achieved after 10000 pulses/site $\left(t_{\text {eff }} \mathbf{1 . 3} \mathrm{ms}\right)$. An additional reduction factor would be related to an influence of the microstructure of the lasercrystallized LSMO films on the saturation magnetization. Our results are in agreement with those reported by Rivas et al. ${ }^{92}$, where the magnetization drastically decreases as the grain size does. Nevertheless, the Curie temperature $\left(T_{c}\right)$ of laser irradiated films, which also increases with the laser effective heating time, is just few tens of degrees lower than the bulk value $(\sim 360 \mathrm{~K}) .{ }^{91}$ In Figure $6 \mathrm{~b}$, we present the magnetic hysteresis loops that illustrate the ferromagnetic behavior of LSMO films. Interestingly, laser processed samples have loops with coercive fields $H_{c}$ of around $300 \mathrm{Oe}$ which are wider than those for thermally annealed samples. Coercive fields usually have a strong dependence on the film microstructure, and tend to increase as the amount of defects in the epitaxial layer does. Although further microstructural characterization is required, it can be expected that laser-crystallized films should present more defects than the thermally annealed ones due to the fast processing times achieved. In addition, we observe a general enhancement of the magnetic properties of LSMO films with longer effective heating times also confirming their relation with the sample crystalline quality.
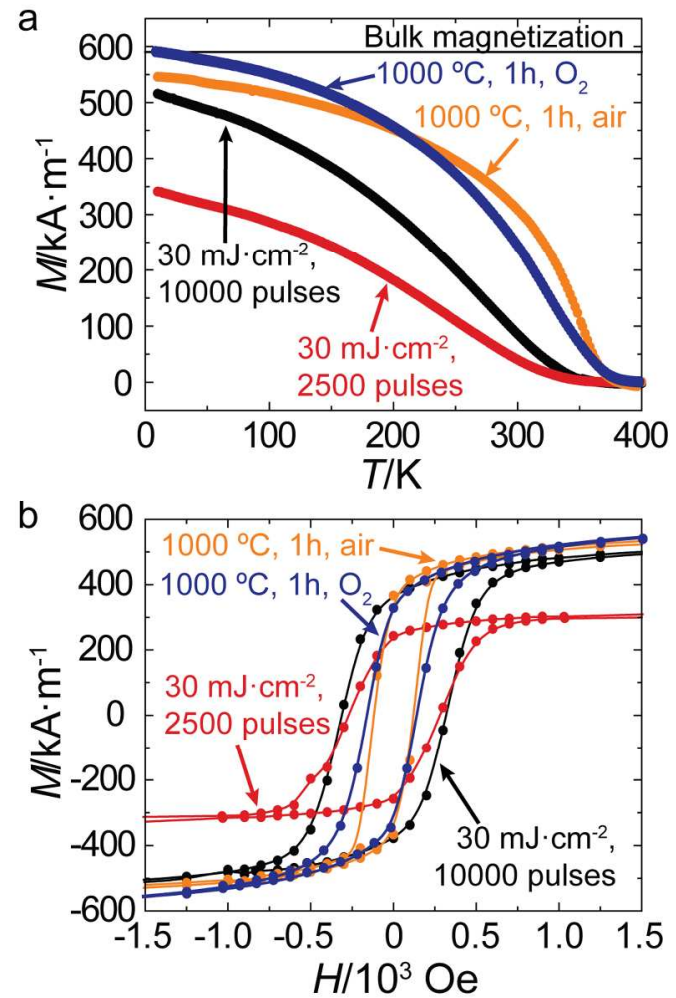

Figure 6. SQUID measurements of LSMO films grown by

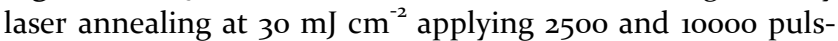
es/site in air, and by thermal annealing at $1000{ }^{\circ} \mathrm{C}, 3^{\circ} \mathrm{C} \mathrm{min}^{-1}$ for $1 \mathrm{~h}$ in air and $\mathrm{O}_{2}$. (a) Magnetization as a function of temperature measured at a constant magnetic field of $5 \mathrm{kOe}$, and (b) magnetization vs magnetic field at a constant temperature of $35 \mathrm{~K}$.

\section{CONCLUSIONS}

Pulsed laser annealing of CSD-derived coatings has been demonstrated to achieve predominantly epitaxial growth of functional oxide heterostructures. The methodology is rather simple and laser irradiations are conducted in air. Despite some optimization of the surface morphology and further irradiation leading to grain boundary healing are still required, we have shown the potential of PLA achieving the crystallization of epitaxial oxide thin films with functional properties close to those reported for conventional thermal treatments, but with orders of magnitude shorter effective heating times. The atomic diffusion coefficients and epitaxial growth rates are orders of magnitude larger than those of thermal treatments. The fast nature of laser-induced heating processes and the development of large temperature gradients is considered to be the main cause of the observed huge growth kinetics. In addition, the fast heating rates are likely preventing excessive coarsening of random orientations which contributes to a fast epitaxial growth. The activation energies for crystallization show smaller values than those obtained with thermal treatments, and indicate that bulk diffusion has a main role in film crystallization. The influence of grain boundary diffusion mechanisms cannot be com- 
pletely discarded given the values of activation energies are not far from the energy range associated to grain boundary diffusion. An additional advancement of this method resides in the ability to locally irradiate (and crystallize) precursor layers. Therefore, we identify the industrial implementation of this technique, by means of direct laser-writing or laser-lithography, as a promising route for future rapid, cost-effective and scalable fabrication of high performance electronic devices.

\section{ASSOCIATED CONTENT}

\section{Supporting Information}

Optical properties of decomposed oxide precursor layers, optical and thermal material properties employed in simulations, photothermal simulations, AFM images of surface morphology, $2 \theta-\chi$, XRR and $2 \mathrm{D}$-XRD measurements. A theoretical description of the self-limited growth is also included, as well as the growth rates and diffusion coefficients extracted. "This material is available free of charge via the Internet at http://pubs.acs.org."

\section{AUTHOR INFORMATION}

\section{Corresponding Author}

*E-mail: albert.queralto.lopez@gmail.com

\section{Author Contributions}

The manuscript was written through contributions of all authors. All authors have given approval to the final version of the manuscript.

\section{Notes}

The authors declare no competing financial interests.

\section{ACKNOWLEDGMENT}

This work was financed by the Ministry of Economy and Competitiveness, and FEDER funds under the projects MAT2011-28874-Co2-O1, MAT2014-51778-C2-1-R, ENE201456109-C3-3-R and Consolider Nanoselect CSD2007-0oo41, and by Generalitat de Catalunya (2009 SGR 770, 2015 SGR 753 and Xarmae). ICMAB acknowledges support from Severo Ochoa Program (MINECO, Grant SEV-2015-0496). AQ and MdIM are also grateful to CSIC and European Social Fund program for JAE-Predoc fellowships (E-o8-2012-1321248 and E-08-2013-1028356).

\section{REFERENCES}

(1) Dawber, M.; Rabe, K. M.; Scott, J. F., Physics of thinfilm ferroelectric oxides. Rev. Mod. Phys. 2005, 77, (4), 1083-1130.

(2) Eerenstein, W.; Mathur, N. D.; Scott, J. F., Multiferroic and magnetoelectric materials. Nature 2006, 442, (7104), 759765 .

(3) Vrejoiu, I.; Alexe, M.; Hesse, D.; Gosele, U., Functional Perovskites - From Epitaxial Films to Nanostructured Arrays. Adv. Funct. Mater. 2008, 18, (24), 3892-3906.

(4) Llordes, A.; Palau, A.; Gazquez, J.; Coll, M.; Vlad, R.; Pomar, A.; Arbiol, J.; Guzman, R.; Ye, S.; Rouco, V.; Sandiumenge, F.; Ricart, S.; Puig, T.; Varela, M.; Chateigner, D.; Vanacken, J.; Gutierrez, J.; Moshchalkov, V.; Deutscher, G.; Magen, C.; Obradors, X., Nanoscale strain-induced pair suppression as a vortex-pinning mechanism in high-temperature superconductors. Nat. Mater. 2012, 11, (4), 329-336.

(5) Murray, E. P.; Tsai, T.; Barnett, S. A., A direct-methane fuel cell with a ceria-based anode. Nature 1999, 400, (6745), 649651.

(6) Lin, W.-H.; Cheng, C.; Hu, C.-C.; Teng, H., $\mathrm{NaTaO}_{3}$ photocatalysts of different crystalline structures for water splitting into $\mathrm{H}_{2}$ and $\mathrm{O}_{2}$. Appl. Phys. Lett. 2006, 89, (21), 211904.

(7) Lange, F. F., Chemical Solution Routes to SingleCrystal Thin Films. Science 1996, 273, (5277), 903-909.

(8) Schwartz, R. W.; Schneller, T.; Waser, R., Chemical solution deposition of electronic oxide films. C. R. Chim. 2004, 7 (5), 433-461.

(9) Obradors, X.; Puig, T.; Gibert, M.; Queraltó, A.; Zabaleta, J.; Mestres, N., Chemical solution route to selfassembled epitaxial oxide nanostructures. Chem. Soc. Rev. 2014, 43, (7), 2200-2225.

(10) Bäuerle, D., Laser Processing and Chemistry. 4th ed.; Springer, Ed. Springer: 2011.

(11) Gyorgy, E.; del Pino, A. P.; Serra, P.; Morenza, J. L., Microcolumn development on titanium by multipulse laser irradiation in nitrogen. J. Mater. Res. 2003, 18, (o9), 2228-2234.

(12) Kang, B.; Han, S.; Kim, J.; Ko, S.; Yang, M., One-Step Fabrication of Copper Electrode by Laser-Induced Direct Local Reduction and Agglomeration of Copper Oxide Nanoparticle. J. Phys. Chem. C 2011, 115, (48), 23664-23670.

(13) Djie, H. S.; Ooi, B. S.; Gunawan, O., Quantum dot intermixing using excimer laser irradiation. Appl. Phys. Lett. 2006, 89, (8), o81901.

(14) Nakajima, T.; Tsuchiya, T., Ion-Exchange Protonation and Enhanced Seed Layer Property of Uniaxially Grown $\mathrm{RbLaNb}_{2} \mathrm{O}_{7}$ Thin Films on Glass Substrates. J. Am. Ceram. Soc. 2012, 95, (2), 573-578.

(15) Queraltó, A.; Pérez del Pino, Á.; Ricart, S.; Obradors, $\mathrm{X}$.; Puig, T., Laser-induced metal organic decomposition for $\mathrm{Ce}_{0.9} \mathrm{Zr}_{0.1} \mathrm{O}_{2-\mathrm{y}}$ epitaxial thin film growth. J. Alloys Compd. 2013, 574, (o), 246-254.

(16) Xue, S.; Ousi-Benomar, W.; Lessard, R. A., Laser beam direct writing of fine lines of alpha- $\mathrm{Fe}_{2} \mathrm{O}_{3}$ from metalorganic spin-coated films and transient behavior study of laser decomposition process. Opt. Eng. 1994, 33, (7), 2442-2448.

(17) Hawelka, D.; Stollenwerk, J.; Pirch, N.; Büsing, L.; Wissenbach, K., Laser Based Inline Production of Wear Protection Coatings on Temperature Sensitive Substrates. Phys. Procedia 2011, 12, Part A, 490-498.

(18) Hawelka, D.; Stollenwerk, J.; Pirch, N.; Wissenbach, K.; Loosen, P., Improving surface properties by laser-based drying, gelation, and densification of printed sol-gel coatings. J. Coating. Tech. Res. 2014, 11, (1), 3-10.

(19) Ghaith, E. S.; Hayakawa, T.; Kasuga, T.; Nogami, M., Apatite formation on rutile type $\mathrm{TiO}_{2}$ films formed by laser irradiation. J. Mater. Sci. 2006, 41, (8), 2521-2524.

(20) Imai, H.; Tominaga, A.; Hirashima, H.; Toki, M.; Aizawa, M., Ultraviolet-laser-induced crystallization of sol-gel derived indium oxide films. J. Sol-Gel Sci. Technol. 1998, 13, (1-3), 991-994.

(21) Baldus, O.; Waser, R., Laser crystallization studies of barium strontium titanate thin films. J. Eur. Ceram. Soc. 2004, 24, (10-11), 3013-3020.

(22) Bharadwaja, S. S. N.; Dechakupt, T.; Trolier-McKinstry, S.; Beratan, H., Excimer laser crystallized $(\mathrm{Pb}, \mathrm{La})(\mathrm{Zr}, \mathrm{Ti}) \mathrm{O}_{3}$ thin films. J. Am. Ceram. Soc. 20o8, 91, (5), 1580-1585.

(23) Queraltó, A.; Pérez del Pino, A.; de la Mata, M.; Tristany, M.; Obradors, X.; Puig, T.; Trolier-McKinstry, S., Ultraviolet pulsed laser crystallization of $\mathrm{Ba}_{0.8} \mathrm{Sr}_{0.2} \mathrm{TiO}_{3}$ films on 
$\mathrm{LaNiO}_{3}$-coated silicon substrates. Ceram. Int. 2016, 42, (3), 40394047.

(24) Asakuma, N.; Fukui, T.; Aizawa, M.; Toki, M.; Imai, H.; Hirashima, H., Ultraviolet-laser-induced crystallization of sol-gel derived inorganic oxide films. J. Sol-Gel Sci. Technol. 20oo, 19, (13), 333-336.

(25) Hsiao, W.-T.; Tseng, S.-F.; Chung, C.-K.; Chiang, D.; Huang, K.-C.; Lin, K.-M.; Li, L.-Y.; Chen, M.-F., Effect on structural, optical and electrical properties of aluminum-doped zinc oxide films using diode laser annealing. Opt. Laser Technol. 2015, 68, 41-47.

(26) El hamali, S. O.; Cranton, W. M.; Kalfagiannis, N.; Hou, X.; Ranson, R.; Koutsogeorgis, D. C., Enhanced electrical and optical properties of room temperature deposited Aluminium doped Zinc Oxide (AZO) thin films by excimer laser annealing. Opt. Laser Eng. 2016, 80, 45-51.

(27) Nishikawa, M.; Nakajima, T.; Kumagai, T.; Okutani, T.; Tsuchiya, T., Photoassisted chemical solution deposition method for fabricating uniformly epitaxial $\mathrm{VO}_{2}$ films. Appl. Phys. A 2010, 100, (1), 297-303.

(28) Nakajima, T.; Tsuchiya, T.; Ichihara, M.; Nagai, H.; Kumagai, T., Epitaxial Growth Mechanism for Perovskite Oxide Thin Films under Pulsed Laser Irradiation in Chemical Solution Deposition Process. Chem. Mater. 20o8, 20, (23), 7344-7351.

(29) Tsuchiya, T.; Nakajima, T.; Kumagai, T., Influence of the laser wavelength on the epitaxial growth and electrical properties of Lao.8Sro.2 $\mathrm{MnO}_{3}$ films grown by excimer laserassisted MOD. Appl. Surf. Sci. 2009, 255, (24), 9804-9807.

(30) Nakajima, T.; Shinoda, K.; Tsuchiya, T., UV-assisted nucleation and growth of oxide films from chemical solutions. Chem. Soc. Rev. 2014, 43, (7), 2027-2041.

(31) Tsuchiya, T.; Yamaguchi, I.; Manabe, T.; Kumagai, T.; Mizuta, S., Low temperature growth of epitaxial complex oxide films by an excimer laser MOD process. Mat. Sci. Eng. B 2004, 109, (1-3), 131-135.

(32) Sohma, M.; Tsuchiya, T.; Tsukada, K.; Yamaguchi, I.; Manabe, T.; Kumagai, T.; Koyanagi, K.; Ebisawa, T.; Ohtsu, H., Preparation of Epitaxial YBCO Films by a Novel Excimer-LaserAssisted MOD. IEEE T. Appl. Supercon. 2007, 17, (2), 3612-3615. (33) Queraltó, A.; Pérez del Pino, A.; de la Mata, M.; Arbiol, J.; Obradors, X.; Puig, T., Ultrafast Crystallization of $\mathrm{Ce}_{0.9} \mathrm{Zr}_{\mathrm{o.1}} \mathrm{O}_{2-\mathrm{y}}$ Epitaxial Films on Flexible Technical Substrates by Pulsed Laser Irradiation of Chemical Solution Derived Precursor Layers. Cryst. Growth Des. 2015, 15, (4), 1957-1967.

(34) Queraltó, A.; Pérez del Pino, A.; de la Mata, M.; Arbiol, J.; Tristany, M.; Gómez, A.; Obradors, X.; Puig, T., Growth of ferroelectric $\mathrm{Ba}_{0.8} \mathrm{Sr}_{0.2} \mathrm{TiO}_{3}$ epitaxial films by ultraviolet pulsed laser irradiation of chemical solution derived precursor layers. Appl. Phys. Lett. 2015, 106, (26), 262903.

(35) Copetti, C. A.; Soltner, H.; Schubert, J.; Zander, W.; Hollricher, O.; Buchal, C.; Schulz, H.; Tellmann, N.; Klein, N., High quality epitaxy of $\mathrm{YBa}_{2} \mathrm{Cu}_{3} \mathrm{O}_{7-x}$ on silicon-on-sapphire with the multiple buffer layer $\mathrm{YSZ} / \mathrm{CeO}_{2}$. Appl. Phys. Lett. 1993, 63, (10), 1429-1431.

(36) Tye, L.; El-Masry, N. A.; Chikyow, T.; McLarty, P.; Bedair, S. M., Electrical characteristics of epitaxial $\mathrm{CeO}_{2}$ on Si(111). Appl. Phys. Lett. 1994, 65, (24), 3081-3083.

(37) Obradors, X.; Puig, T.; Pomar, A.; Sandiumenge, F.; Mestres, N.; Coll, M.; Cavallaro, A.; Roma, N.; Gazquez, J.; Gonzalez, J. C.; Castano, O.; Gutierrez, J.; Palau, A.; Zalamova, K.; Morlens, S.; Hassini, A.; Gibert, M.; Ricart, S.; Moreto, J. M.; Pinol, S.; Isfort, D.; Bock, J., Progress towards all-chemical superconducting $\mathrm{YBa}_{2} \mathrm{Cu}_{3} \mathrm{O}_{7}$-coated conductors. Supercond. Sci. Technol. 2006, 19, (3), S13-S26.
(38) Bao, D.; Yao, X.; Wakiya, N.; Shinozaki, K.; Mizutani, N., Preparation of conductive $\mathrm{LaNiO}_{3}$ film electrodes by a simple chemical solution deposition technique for integrated ferroelectric thin film devices. J. Phys. D Appl. Phys. 2003, 36, (10), 1217-1221.

(39) Galal, A.; Atta, N. F.; Ali, S. M., Optimization of the synthesis conditions for $\mathrm{LaNiO}_{3}$ catalyst by microwave assisted citrate method for hydrogen production. Appl. Catal. A 2011, 409-410, (o), 202-208.

(40) Setter, N.; Damjanovic, D.; Eng, L.; Fox, G.; Gevorgian, S.; Hong, S.; Kingon, A.; Kohlstedt, H.; Park, N. Y.; Stephenson, G. B.; Stolitchnov, I.; Taganstev, A. K.; Taylor, D. V.; Yamada, T.; Streiffer, S., Ferroelectric thin films: Review of materials, properties, and applications. J. Appl. Phys. 2006, 100, (5), 05160646.

(41) Tombak, A.; Maria, J. P.; Ayguavives, F.; Stauf, G. T.; Kingon, A. I.; Mortazawi, A., Tunable barium strontium titanate thin film capacitors for RF and microwave applications. IEEE Microw. Compon. Lett. 2002, 12, (1), 3-5.

(42) Zhang, J.; Cole, M. W.; Alpay, S. P., Pyroelectric properties of barium strontium titanate films: Effect of thermal stresses. J. Appl. Phys. 2010, 108, (5), 054103-7.

(43) Tokura, Y., Critical features of colossal magnetoresistive manganites. Rep. Prog. Phys. 20o6, 69, (3), 797851.

(44) Coey, J. M. D.; Viret, M.; von Molnár, S., Mixed-valence manganites. Adv. Phys. 1999, 48, (2), 167-293.

(45) Martin, L. W.; Chu, Y. H.; Ramesh, R., Advances in the growth and characterization of magnetic, ferroelectric, and multiferroic oxide thin films. Mat. Sci. Eng. R 2o10, 68, (4-6), 89133.

(46) Moreno, C.; Munuera, C.; Valencia, S.; Kronast, F.; Obradors, X.; Ocal, C., Reversible Resistive Switching and Multilevel Recording in Lao.7Sro.3 $\mathrm{MnO}_{3}$ Thin Films for Low Cost Nonvolatile Memories. Nano Lett. 2o1o, 10, (10), 3828-3835. (47) Roura, P.; Farjas, J.; Ricart, S.; Aklalouch, M.; Guzman, R.; Arbiol, J.; Puig, T.; Calleja, A.; Peña-Rodríguez, O.; Garriga, M.; Obradors, X., Synthesis of nanocrystalline ceria thin films by low-temperature thermal decomposition of Ce-propionate. Thin Solid Films 2012, 520, (6), 1949-1953.

(48) Coll, M.; Palau, A.; Gonzalez-Rosillo, J. C.; Gazquez, J.; Obradors, X.; Puig, T., Integration of atomic layer deposition $\mathrm{CeO}_{2}$ thin films with functional complex oxides and ${ }_{3} \mathrm{D}$ patterns. Thin Solid Films 2014, 553, (o), 7-12.

(49) Queraltó, A. Growth of functional oxide heterostructures from chemical solutions using advanced processing methodologies. Universitat Autònoma de Barcelona, 2015.

(50) van der Pauw, L. J., A Method of Measuring the Resistivity and Hall Coefficient on Lamellae of Arbitrary Shape. Philips Tech. Rev. 1958, 20, 220-224.

(51) Denton, R. E.; Tomlin, S. G.; Campbell, R. D., The determination of Optical-Constants of Thin-Films from Measurements of Reflectance and Transmittance at Normal Incidence. J. Phys. D Appl. Phys. 1972, 5, (4), 852-863.

(52) Anjana, P. S.; Deepu, V.; Uma, S.; Mohanan, P.; Philip, J.; Sebastian, M. T., Dielectric, Thermal, and Mechanical Properties of $\mathrm{CeO}_{2}$-Filled HDPE Composites for Microwave Substrate Applications. J. Polym. Sci. Pol. Phys. 2010, 48, (9), 998-1008.

(53) Riess, I.; Ricken, M.; No"lting, J., On the specific heat of nonstoichiometric ceria. J. Solid State Chem. 1985, 57, (3), 314322. 
(54) Degueldre, C.; Tissot, P.; Lartigue, H.; Pouchon, M., Specific heat capacity and Debye temperature of zirconia and its solid solution. Thermochim. Acta 2003, 403, (2), 267-273.

(55) Schlichting, K. W.; Padture, N. P.; Klemens, P. G., Thermal conductivity of dense and porous yttria-stabilized zirconia. J. Mater. Sci. 2001, 36, (12), 3003-3010.

(56) Lai, S. C.; Lue, H. T.; Hsieh, K. Y.; Lung, S. L.; Liu, R.; Wu, T. B.; Donohue, P. P.; Rumsby, P., Extended-pulse excimer laser annealing of $\mathrm{Pb}\left(\mathrm{Zr}_{1-\mathrm{x}} \mathrm{Ti}_{\mathrm{x}}\right) \mathrm{O}_{3}$ thin film on $\mathrm{LaNiO}_{3}$ electrode. J. Appl. Phys. 2004, 96, (5), 2779-2784.

(57) Mistrik, J.; Yamaguchi, T.; Franta, D.; Ohlidal, I.; Hu, G. J.; Dai, N., Optical properties of rough $\mathrm{LaNiO}_{3}$ thin films studied by spectroscopic ellipsometry and reflectometry. Appl. Surf. Sci. 2005, 244, (1-4), 431-434.

(58) Zinkevich, M.; Aldinger, F., Thermodynamic analysis of the ternary La-Ni-O system. J. Alloys Compd. 2004, 375, (1-2), 147-161.

(59) Muta, H.; Ieda, A.; Kurosaki, K.; Yamanaka, S., Thermoelectric Properties of Lanthanum-Doped Europium Titanate. Mater. Trans. 2005, 46, (7), 1466-1469.

(6o) Smith, J. R.; Chen, A.; Gostovic, D.; Hickey, D.; Kundinger, D.; Duncan, K. L.; DeHoff, R. T.; Jones, K. S.; Wachsman, E. D., Evaluation of the relationship between cathode microstructure and electrochemical behavior for SOFCs. Solid State Ion. 2009, 180, (1), 90-98.

(61) Wang, L. M.; Lai, J.-H.; Wu, J.-I.; Kuo, Y.-K.; Chang, C. L., Effects of $\mathrm{Ru}$ substitution for $\mathrm{Mn}$ on $\mathrm{La}_{0.7} \mathrm{Sr}_{0.3} \mathrm{MnO}_{3}$ perovskites. J. Appl. Phys. 2007, 102, (2), 023915.

(62) Cardona, M., Optical Properties and Band Structure of $\mathrm{SrTiO}_{3}$ and $\mathrm{BaTiO}_{3}$. Phys. Rev. 1965, 140, (2A), A651.

(63) de Ligny, D.; Richet, P., High-temperature heat capacity and thermal expansion of $\mathrm{SrTiO}_{3}$ and $\mathrm{SrZrO}_{3}$ perovskites. Phys. Rev. B 1996, 53, (6), 3013.

(64) Davitadze, S. T.; Kravchun, S. N.; Strukov, B. A.; Goltzman, B. M.; Lemanov, V. V.; Shulman, S. G., Specific heat and thermal conductivity of $\mathrm{BaTiO}_{3}$ polycrystalline thin films. Appl. Phys. Lett. 2002, 8o, (9), 1631-1633.

(65) Michael, P. C.; Trefny, J. U.; Yarar, B., Thermal Transport-Properties of Single-Crystal Lanthanum Aluminate. J. Appl. Phys. 1992, 72, (1), 107-109.

(66) Zeng, X.; Zhang, L.; Zhao, G.; Xu, J.; Hang, Y.; Pang, H.; Jie, M.; Yan, C.; He, X., Crystal growth and optical properties of $\mathrm{LaAlO}_{3}$ and Ce-doped $\mathrm{LaAlO}_{3}$ single crystals. J. Cryst. Growth 2004, 271, (1-2), 319-324.

(67) Speight, J., Lange's handbook of chemistry. McGrawHill: New York, 2005.

(68) Serna, R.; Afonso, C. N.; Petford-Long, A. K.; Long, N. J., Structural ripple formation in $\mathrm{Ge} / \mathrm{Sb}$ multilayers induced by laser irradiation. Appl. Phys. A 1994, 58, (2), 197-202.

(69) Martín-Fabiani, I.; Rebollar, E.; Pérez, S.; Rueda, D. R.; García-Gutiérrez, M. C.; Szymczyk, A.; Roslaniec, Z.; Castillejo, M.; Ezquerra, T. A., Laser-Induced Periodic Surface Structures Nanofabricated on Poly(trimethylene terephthalate) SpinCoated Films. Langmuir 2012, 28, (20), 7938-7945.

(7o) Hassini, A.; Pomar, A.; Gutierrez, J.; Coll, M.; Roma, N.; Moreno, C.; Ruyter, A.; Puig, T.; Obradors, X., Atomically flat MOD $\mathrm{La}_{0.7} \mathrm{Sr}_{0.3} \mathrm{MnO}_{3}$ buffer layers for high critical current $\mathrm{YBa}_{2} \mathrm{Cu}_{3} \mathrm{O}_{7}$ TFA films. Supercond. Sci. Technol. 2007, 20, (9), $\mathrm{S}_{230}-\mathrm{S}_{23} 8$

(71) Guo, Y.; Suzuki, K.; Nishizawa, K.; Miki, T.; Kato, K., Dielectric and piezoelectric properties of highly (10o)-oriented $\mathrm{BaTiO}_{3}$ thin film grown on a $\mathrm{Pt} / \mathrm{TiO}_{\mathrm{x}} / \mathrm{SiO}_{2} / \mathrm{Si}$ substrate using $\mathrm{LaNiO}_{3}$ as a buffer layer. J. Cryst. Growth 2005, 284, (1-2), 190196.
(72) Rupp, J. L. M.; Infortuna, A.; Gauckler, L. J., Microstrain and self-limited grain growth in nanocrystalline ceria ceramics. Acta Mater. 2oo6, 54, (7), 1721-1730.

(73) Rupp, J. L. M.; Scherrer, B.; Harvey, A. S.; Gauckler, L. J., Crystallization and Grain Growth Kinetics for PrecipitationBased Ceramics: A Case Study on Amorphous Ceria Thin Films from Spray Pyrolysis. Adv. Funct. Mater. 20o9, 19, (17), 27902799.

(74) Mehrer, H., Diffusion in Solids: Fundamentals, Methods, Materials, Diffusion-Controlled Processes. Springer: Berlin, 2007; Vol. 155.

(75) Avrami, M., Kinetics of phase change I - General theory. J. Chem. Phys. 1939, 7, (12), 1103-1112.

(76) Avrami, M., Kinetics of Phase Change. II Transformation-Time Relations for Random Distribution of Nuclei. J. Chem. Phys. 1940, 8, (2), 212-224.

(77) Bharadwaja, S. S. N.; Kulik, J.; Akarapu, R.; Beratan, H.; Trolier-McKinstry, S., Ultrafast crystallization kinetics in $(\mathrm{Pb}, \mathrm{La})\left(\mathrm{Zr}_{0.30} \mathrm{Ti}_{0.7 \mathrm{o}}\right) \mathrm{O}_{3}$ thin films by pulsed excimer laser annealing. IEEE T. Ultrason. Ferr. 2010, 57, (10), 2182-2191.

(78) Heiroth, S.; Frison, R.; Rupp, J. L. M.; Lippert, T.; Barthazy Meier, E. J.; Müller Gubler, E.; Döbeli, M.; Conder, K.; Wokaun, A.; Gauckler, L. J., Crystallization and grain growth characteristics of yttria-stabilized zirconia thin films grown by pulsed laser deposition. Solid State Ion. 2011, 191, (1), 12-23.

(79) Farjas, J.; Roura, P., Modification of the KolmogorovJohnson-Mehl-Avrami rate equation for non-isothermal experiments and its analytical solution. Acta Mater. 2006, 54, (20), 5573-5579.

(80) Schneller, T.; Waser, R.; Kosec, M.; Payne, D., Chemical Solution Deposition of Functional Oxide Thin Films. Springer London, Limited: 2013.

(81) Kuo, C.-W.; Lee, Y.-H.; Hung, I. M.; Wang, M.-C.; Wen, S.-B.; Fung, K.-Z.; Shih, C.-J., Crystallization kinetics and growth mechanism of $8 \mathrm{~mol} \%$ yttria-stabilized zirconia (8YSZ) nanopowders prepared by a sol-gel process. J. Alloys Compd. 20o8, 453, (1-2), 470-475.

(82) Lai, J. K. L.; Shek, C. H.; Lin, G. M., Grain growth kinetics of nanocrystalline $\mathrm{SnO}_{2}$ for long-term isothermal annealing. Scripta Mater. 2003, 49, (5), 441-446.

(83) Jud, E.; Huwiler, C. B.; Gauckler, L. J., Sintering Analysis of Undoped and Cobalt Oxide Doped Ceria Solid Solutions. J. Am. Ceram. Soc. 2005, 88, (11), 3013-3019.

(84) Sánchez, R. D.; Causa, M. T.; Caneiro, A.; Butera, A.; Vallet-Regí, M.; Sayagués, M. J.; González-Calbet, J.; García-Sanz, F.; Rivas, J., Metal-insulator transition in oxygen-deficient $\mathrm{LaNiO}_{3}$ perovskites. Phys. Rev. B 1996, 54, (23), 16574-16578.

(85) Sreedhar, K.; Honig, J. M.; Darwin, M.; McElfresh, M.; Shand, P. M.; Xu, J.; Crooker, B. C.; Spalek, J., Electronic properties of the metallic perovskite $\mathrm{LaNiO}_{3}$ : Correlated behavior of 3 d electrons. Phys. Rev. B 1992, 46, (10), 6382-6386.

(86) Reichmann, K.; Schneller, T.; Hoffmann-Eifert, S.; Hasenkox, U.; Waser, R., Morphology and electrical properties of $\mathrm{SrTiO}_{3}$-films on conductive oxide films. J. Eur. Ceram. Soc. 20o1, 21, (10-11), 1597-160o.

(87) Meng, X.-J.; Sun, J.-L.; Yu, J.; Ye, H.-J.; Guo, S.-L.; Chu, J.-H., Preparation of highly (1 o o)-oriented metallic $\mathrm{LaNiO}_{3}$ films on $\mathrm{Si}$ substrates by a modified metalorganic decomposition technique. Appl. Surf. Sci. 20o1, 171, (1-2), 68-70.

(88) Obradors, X.; Martínez-Julián, F.; Zalamova, K.; Vlad, V. R.; Pomar, A.; Palau, A.; Llordés, A.; Chen, H.; Coll, M.; Ricart, S.; Mestres, N.; Granados, X.; Puig, T.; Rikel, M., Nucleation and mesostrain influence on percolating critical currents of solution derived $\mathrm{YBa}_{2} \mathrm{Cu}_{3} \mathrm{O}_{7}$ superconducting thin films. Physica $C$ Supercond. 2012, 482, (o), 58-67. 


\section{Page 13 of 14}

1

2

3

4

5

6

7

8

9

10

11

12

13

14

15

16

17

18

19

20

21

22

23

24

25

26

27

28

29

30

31

32

33

34

35

36

37

38

39

40

41

42

43

44

45

46

47

48

49

50

51

52

53

54

55

56

57

58

59

60
(89) Yin, Q.; Zhu, B.; Zeng, H., Microstructure, Property and Processing of Functional Ceramics. Springer Berlin Heidelberg: Berlin, Heidelberg, 2010.

(90) Balke, N.; Maksymovych, P.; Jesse, S.; Kravchenko, I. I.; Li, Q.; Kalinin, S. V., Exploring local electrostatic effects with ccanning probe microscopy: Implications for piezoresponse force microscopy and triboelectricity. ACS Nano 2014, 8, (10), 10229-10236.

(91) Moreno, C.; Abellan, P.; Sandiumenge, F.; Casanove, M. J.; Obradors, X., Nanocomposite lanthanum strontium manganite thin films formed by using a chemical solution deposition. Appl. Phys. Lett. 2012, 100, (2), 023103.

(92) Rivas, J.; Hueso, L. E.; Fondado, A.; Rivadulla, F.; López-Quintela, M. A., Low field magnetoresistance effects in fine particles of $\mathrm{La}_{0.67} \mathrm{Ca}_{0.33} \mathrm{MnO}_{3}$ perovskites. J. Magn. Magn. Mater. 2000, 221, (1-2), 57-62. 
SYNOPSIS TOC

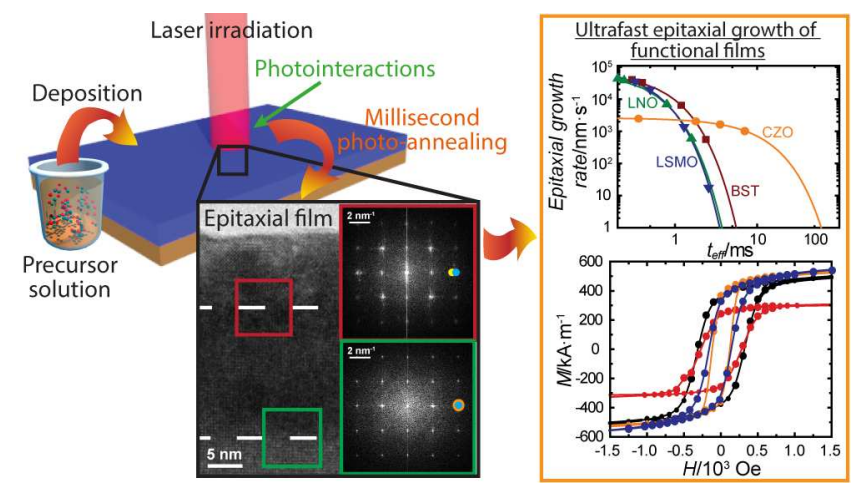

Ultrafast epitaxial growth of oxide thin films is demonstrated by pulsed laser annealing. The fast crystallization achieved by photo-induced interactions, i.e. orders of magnitude larger than thermal treatments, is mainly driven by bulk diffusion. The films also reveal good functional properties in some cases equivalent to those produced by thermal treatments. 